$06.4 ; 09$

\title{
Пластическая деформация меди в результате воздействия мощного ультрафиолетового наносекундного лазерного импульса
}

\author{
(C) Т.В. Малинский ${ }^{1}$, С.И. Миколуцкий ${ }^{1}$, В.Е. Рогалин ${ }^{1, \uparrow, ~ Ю . В . ~ Х о м и ч ~}{ }^{1}$, В.А. Ямщиков ${ }^{1}$, И.А. Каплунов ${ }^{2}$, \\ А.И. Иванова ${ }^{2}$ \\ ${ }^{1}$ Институт электрофизики и электроэнергетики РАН, Санкт-Петербург, Россия \\ ${ }^{2}$ Тверской государственный университет, Тверь, Россия \\ ฯ E-mail: v-rogalin@mail.ru
}

Поступило в Редакцию 17 декабря 2019г.

В окончательной редакции 15 мая 2020г.

Принято к публикации 22 мая 2020г.

Исследована модификация полированной поверхности бескислородной меди после воздействия жестко сфокусированным одиночным импульсом ультрафиолетового Nd:YAG-лазера. Выявлено, что при предпороговых плотностях энергии (при $E \sim 0.6 \mathrm{~J} / \mathrm{cm}^{2}$ ) в отсутствие заметных следов абляции наблюдалось необратимое поднятие поверхности металла в зоне облучения. При увеличении плотности энергии абляционные процессы заметно нивелируют этот эффект.

Ключевые слова: УФ-лазер, наносекундный импульс, порог оптического пробоя, абляция, термодеформация.

DOI: 10.21883/PJTF.2020.16.49856.18157

Наносекундные импульсы УФ-лазера способны модифицировать поверхность металла, существенно изменяя его поверхностные свойства [1-4]. Диффузионная сварка металлов, обработанных подобным образом, заметно улучшается благодаря интенсификации диффузионных процессов в зоне контакта соединяемых поверхностей [5]. Обычно основное внимание при воздействии лазерного излучения (ЛИ) уделялось исследованию явлений плавления, испарения и абляции [2,6-10] процессам, сопряженным с переходом вещества в другое агрегатное состояние $[3,6]$.

Однако иногда при воздействии импульсного ЛИ наблюдались необычные признаки возникновения различных нестационарных процессов, связанных с резко ускоренным перемещением ионов в объеме твердого тела [11-13]. Эти работы, проведенные с использованием лазеров с различающимися длинами волн ЛИ и длительностями импульсов, а также на различных материалах, не нашли должной теоретической интерпретации и недостаточно освещены в обзорах и монографиях.

В настоящей работе исследовалась полированная бескислородная медь после обработки наносекундными лазерными импульсами УФ-диапазона. Излучателем был импульсно-периодический $\mathrm{Nd}$ :YAG-лазер (третья гармоника, длина волны $\lambda=355 \mathrm{~nm}$, энергия в импульсе до $8 \mathrm{~mJ}$ при длительности $\tau=10 \mathrm{~ns})$. Полированная медь на длине волны $\lambda=355 \mathrm{~nm}$ поглощает $\sim 90 \%$, тогда как на длине волны $\lambda=1060 \mathrm{~nm}-3-4 \%$ (спектры измерены в ИЛМЗ НИТУ „МИСиС“). Изменялись энергия и число воздействующих импульсов ЛИ. После воздействия ЛИ поверхность исследовалась на оптическом профилометре Zygo NewView 7300 и растровом электронном микроскопе (РЭМ) JEOL JSM 6610LV. Исходная шероховатость поверхности на участке, сопоста- вимом с площадью лазерного пятна, составляла приблизительно 10-15 nm. На рис. 1, $а$ приведена РЭМ-микрофотография образца после воздействия пяти импульсов с плотностью энергии $E \sim 0.6 \mathrm{~J} / \mathrm{cm}^{2}$, на рис. $1, b-$ после воздействия одного импульса с $E \sim 6.2 \mathrm{~J} / \mathrm{cm}^{2}$, на рис. $1, c$ - после воздействия пяти импульсов с $E \sim 2.3 \mathrm{~J} / \mathrm{cm}^{2}$. На рис. 2 представлены соответствующие профилограммы.

Анализ профиля поверхности меди после воздействия ЛИ показывает, что при $E \sim 0.6 \mathrm{~J} / \mathrm{cm}^{2}$ в отсутствие заметных следов абляции наблюдалось необратимое неравномерное поднятие поверхности металла в зоне облучения на несколько десятков нанометров (рис. $1, a, 2, a)$. Профиль уровня такого поднятия приблизительно соответствует распределению лазерной энергии в пятне.

При $E \geqslant 1.0 \mathrm{~J} / \mathrm{cm}^{2}$ происходил оптический пробой, сопровождавшийся абляционными процессами, что в итоге привело к изменению структуры поверхностного слоя (рис. $1, b, 2, b ; E \sim 6.2 \mathrm{~J} / \mathrm{cm}^{2}$ ). Профиль поверхности приобрел характерный для режима абляции резко неоднородный вид. Перепад высот составлял величину до нескольких микрометров. Зафиксированы следы плавления и частичного испарения поверхностного слоя с последующей быстрой кристаллизацией.

Анализ РЭМ-микрофотографий и оценки по приведенной далее формуле (1) позволили предположить, что за счет нагрева ЛИ при $E \sim 0.6 \mathrm{~J} / \mathrm{cm}^{2}$ удалось достичь на поверхности меди предплавильной температуры. Пороговая плотность энергии плавления с учетом удельной теплоты плавления составляет [14]:

$$
E_{m}(\tau)=\delta(\tau) \rho\left[C\left(T_{m}-T_{i n}\right)+L_{m}\right],
$$

где $\delta(\tau)$ имеет физический смысл эффективной толщины слоя, в котором происходит выделение энергии лазер- 


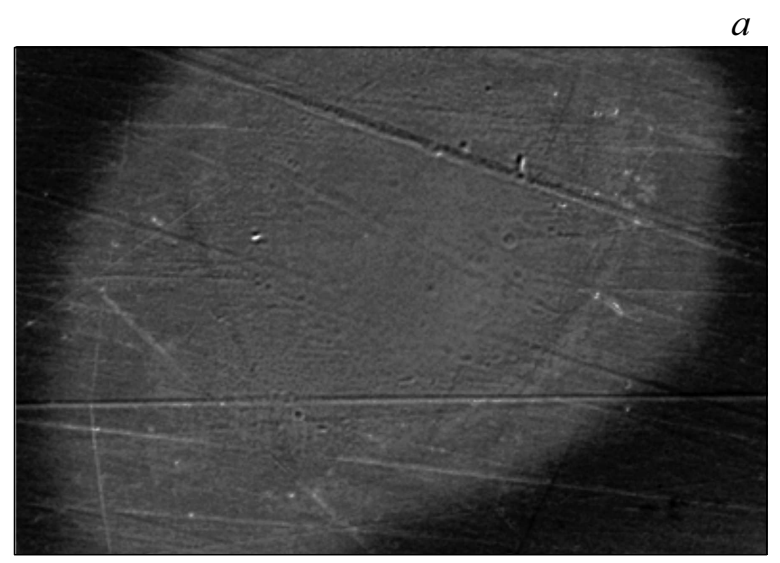

$10 \mu \mathrm{m}$

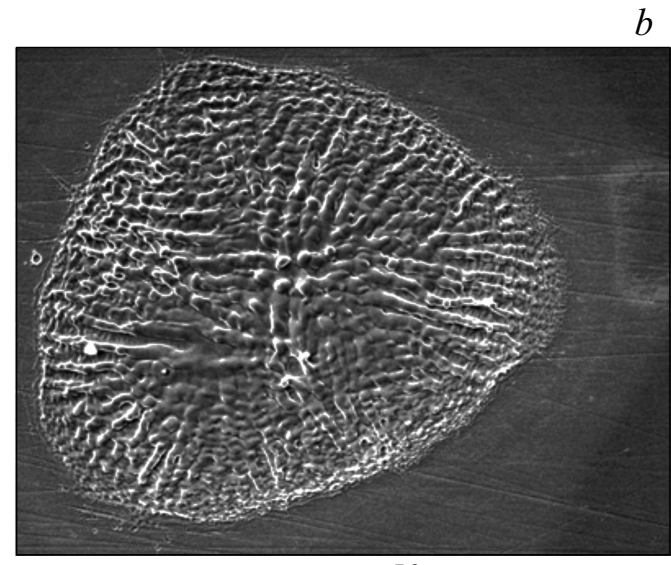

$50 \mu \mathrm{m}$

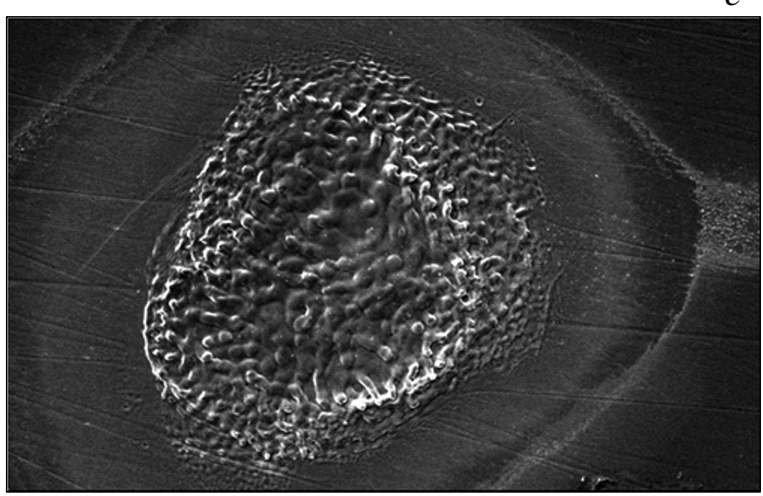

$50 \mu \mathrm{m}$

Рис. 1. РЭМ-микрофотография поверхности бескислородной меди после облучения Nd:YAG-лазером $(\lambda=355 \mathrm{~nm}): a-$ пять импульсов с $E \sim 0.6 \mathrm{~J} / \mathrm{cm}^{2}, b-$ один импульс с $E \sim 6.2 \mathrm{~J} / \mathrm{cm}^{2}, c-$ пять импульсов с $E \sim 2.3 \mathrm{~J} / \mathrm{cm}^{2}$.

ного нагрева в материале во время импульса длительностью $\tau$, а символами $\rho, C, T_{m}, T_{i n}, L_{m}$ обозначены плотность, удельная теплоемкость, температура плавления, начальная температура и скрытая теплота плавления материала соответственно. В случае поверхностного нагрева

$$
\delta(\tau)=\frac{1}{2}(\pi a \tau)^{1 / 2}
$$

где $a$ - температуропроводность материала.

Оценки для меди с учетом (1) и (2) при $C=385 \mathrm{~J} /(\mathrm{kg} \cdot \mathrm{K}), \rho=8920 \mathrm{~kg} / \mathrm{m}^{3}, \quad a=1.2 \cdot 10^{-4} \mathrm{~m}^{2} / \mathrm{s}$, $T_{m}=1356 \mathrm{~K}, T_{i n}=293 \mathrm{~K}, L_{m}=204.7 \cdot 10^{3} \mathrm{~J} / \mathrm{kg}$ [15] для $\tau=10 \mathrm{~ns}$ дают следующие значения: $\delta(\tau)=971 \mathrm{~nm}$, $E_{m}(\tau)=0.53 \mathrm{~J} / \mathrm{cm}^{2}$.

Эксперимент показал, что подъем поверхности стабильно наблюдался до появления оптического пробоя (при $E<1.0 \mathrm{~J} / \mathrm{cm}^{2}$ ).

Проведена оценка высоты подъема поверхности, основанная на анализе протекания процесса необратимой термодеформации меди вблизи поверхности при усредненной температуре поверхностного слоя меди $T \sim 1350 \mathrm{~K}$. За время длительности импульса $\tau$ тепло распространяется на глубину $h$

$$
h=2 \sqrt{a \tau}=2.2 \mu \mathrm{m},
$$

где $a-$ температуропроводность меди $\left(1.2 \cdot 10^{-4} \mathrm{~m}^{2} / \mathrm{s}[15]\right), \tau=10 \mathrm{~ns}$.

Поскольку произошел резкий нагрев локального облучаемого объема, его термическое расширение произошло преимущественно в направлении свободной поверхности. В этом случае величина поднятия $\Delta h$ составляет

$$
\Delta h=K h\left(T-T_{i n}\right) \approx 40 \mathrm{~nm},
$$

где $K$ - коэффициент термического расширения меди $\left(17 \cdot 10^{-6} \mathrm{~K}^{-1}\right)[15], T_{\text {in }}$ - начальная температура, приблизительно равная $300 \mathrm{~K}$.

Если допустить, что наблюдавшийся эффект имел накопительный характер, то после пяти импульсов поднятие поверхности может составить около 100-200 nm, что по порядку величины совпадает с данными проведенного эксперимента (рис. 1, $a, 2, a)$. С учетом того, что поднятие поверхности в пятне произошло за время $\tau$, можно оценить скорость процесса, которая составила $\sim 1 \mathrm{~m} / \mathrm{s}$.

К сожалению, получить данные о результатах воздействия большего числа импульсов предпороговой мощности на наши образцы пока не удалось, так как после 

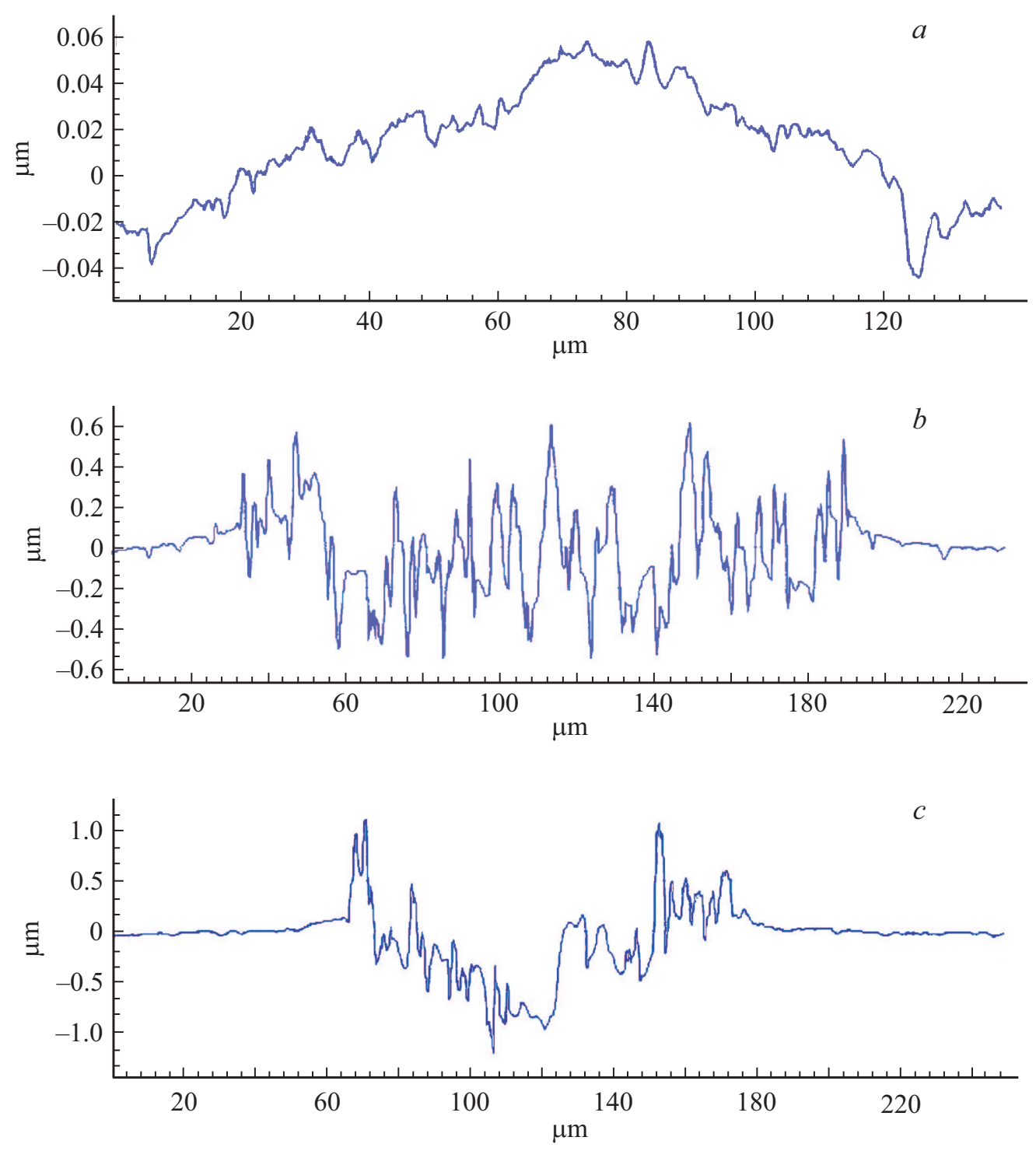

Рис. 2. Профиль поверхности меди в пятне облучения: $a-$ пять импульсов с $E \sim 0.6 \mathrm{~J} / \mathrm{cm}^{2}, b-$ один импульс с $E \sim 6.2 \mathrm{~J} / \mathrm{cm}^{2}$, $c$ - пять импульсов с $E \sim 2.3 \mathrm{~J} / \mathrm{cm}^{2}$.

воздействия тремя-пятью импульсами при используемой мощности ЛИ, как правило, возникал оптический пробой с образованием абляционного слоя, резко изменяющего профиль поверхности. Мы предполагаем, что этот эффект может быть связан с созданием на первоначально полированной поверхности заметной неравномерности, снижающей порог оптического пробоя [16].

Дальнейшее увеличение как мощности воздействующих импульсов, так и их количества приводило к появлению заметного кратерообразования (рис. 1, $c$ и 2,c).

На профилограммах и микрофотографиях (рис. 1, 2) отчетливо видно, что профиль поверхности в зоне воздействия ЛИ приобрел резко неравномерный характер. Продекорированы некоторые мелкие царапины и, по-видимому, некоторые другие дефекты приповерхностного слоя. В то же время часть мелких царапин, проходящих через облученную область, в зоне воздействия не наблюдалась. Резкий рост шероховатости, видимо, обусловлен температурной активацией структурных дефектов металла (дислокаций, границ зерен и др.), вызвавшей их движение в сторону свободной поверхности, что в итоге привело к пластической деформации. Возможно, как и в работе [11], произошла передача части энергии лазерного импульса в кристаллическую решетку металла и в наблюдавшемся явлении принимает участие и объем образца.

Таким образом, при воздействии ЛИ на полированную поверхность меди обнаружены два процесса, частично компенсирующие друг друга. Это абляция материала в зоне воздействия при $E \geqslant 1.0 \mathrm{~J} / \mathrm{cm}^{2}$ и не наблюдавшийся ранее эффект неравномерного поднятия поверхности меди в этой зоне при $E \sim 0.5-1.0 \mathrm{~J} / \mathrm{cm}^{2}$. С увеличением количества импульсов происходило кратерообразование в зоне воздействия. 


\section{Конфликт интересов}

Авторы заявляют, что у них нет конфликта интересов.

\section{Список литературы}

[1] Fraggelakis F., Mincuzzi G., Manek-H"onninger I., Lopez J., Klinga R. // RSC Adv. 2018. V. 8. N 29. P. 16082-16087.

[2] Csizmadia T., Smausz T., Tápai C., Kopniczky J., Wang X., Ehrhardt M., Lorenz P., Zimmer K., Orosz L., Varga E., Oszkó A., Hopp B. // J. Laser Micro/Nanoeng. 2015. V. 10. N 2. P. $110-118$.

[3] Железнов Ю.А., Малинский Т.В., Миколуцкий С.И., Хасая Р.Р., Хомич Ю.В., Ямщиков В.А. // Письма о материалах. 2014. Т. 4. № 1. С. 45-48.

[4] Luo F., Ong W., Guan Y., Li F., Sun S., Lim G.C., Hong M. // Appl. Surf. Sci. 2015. V. 328. P. 405-409.

[5] Вашуков Ю.А., Демичев С.Ф., Еленев В.Д., Малинский Т.В., Миколуцкий С.И., Хомич Ю.В., Ямщиков В.А. // Прикладная физика. 2019. № 1. С. 82-87.

[6] Хомич В.Ю., Шмаков В.А. // УФН. 2015. Т. 185. № 5. C. 489-499.

[7] Гуренцов Е.В., Еремин А.В., Мусихин С.А. // ЖТФ. 2019. T. 89. В. 8. C. $1200-1207$.

[8] Старинский С.В., Шухов Ю.Г., Булгаков А.В. // Письма в ЖТФ. 2016. Т. 42. В. 8. С. 45-52.

[9] Khomich V.Yu., Urlichich Yu.M., Shmakov V.A., Tokarev V.N., Galstyan A.M., Mikolutskiy S., Malinskiy T.V., Ganin D.V. // Inorganic Mater:: Appl. Res. 2013. V. 4. N 3. P. 201-204.

[10] Вейко В.П., Сквориов А.М., Конг Т.Х., Петров А.А. // Письма в ЖТФ. 2015. Т. 41. В. 14. С. 79-87.

[11] Ровинский Р.Е., Рогалин В.Е., Розенберг В.М., Теплицкий М.Д. // Физика и химия обраб. материалов. 1980. № 3. C. 7-11.

[12] Гуревич М.Е., Лариков Л.Н., Мазанко В.Ф., Погорелов А.Е., Фальченко В.М. // Металлофизика. 1978. В. 73. C. 80-83.

[13] Vegel K., Beckland P. // J. Appl. Phys. 1965. V. 36. N 12. P. 3697-3701.

[14] Токарев В.Н., Чешев Е.А., Малинский Т.В., Хомич Ю.В., Ямщиков В.А., Железнов Ю.А., Безотосный В.В., Артемов В.Г. // Успехи прикладной физики. 2013. Т. 1. № 6. C. 686-691.

[15] Николаев А.К., Костин С.А. Медь и жаропрочные медные сплавы М.: ДПК Пресс, 2012. 715 с.

[16] Бломберген Н. // Квантовая электроника. 1974. Т. 1. № 4. C. $786-805$. 